Review

\title{
Antimicrobial Resistance Pattern of Pseudomonas aeruginosa from Different Clinical Specimens: Survey Article
}

\author{
Hosniyeh E. Ladadweh, Hiba H. Falana, Jannat M. Ma'ali, \\ Pinar A. Aweis, Hanan N. Nofal and Hani A. Naseef* \\ Department of Pharmacy, Faculty of Pharmacy, Nursing and Health Professions, Birzeit University, Palestine
}

\author{
Article history \\ Received: 27-10-2020 \\ Revised: 11-01-2021 \\ Accepted: 11-01-2021 \\ Corresponding Author: \\ Hani A. Naseef \\ Department of Pharmacy, \\ Faculty of Pharmacy, Nursing \\ and Health Professions, Birzeit \\ University, Palestine \\ Email: hshtaya@birzeit.edu
}

\begin{abstract}
Pseudomonas aeruginosa (P.A.) is a gram-negative, aerobic rod bacterium that mainly grows in soil and watery environments, infrequently being a part of microflora in healthy individuals. Since P.A. favors the growth in moistened areas, it can colonize in any simple aqueous solution, which in turn raises the risk of contamination and infection in hospital settings. The emergence of drug resistant bacterial species has become increasingly prevalent in many health care facilities worldwide. Pseudomonas aeruginosa is one of these pathogens that had developed resistance to many of the previously effective antibiotics. Hence, it is highly valued to know the resistance pattern of P.A. in every health care facility. That in turn would facilitate more accurate and effective empirical regimens selection when dealing with life threatening infections. The purpose of this study is to review antimicrobial resistance patterns of $P$. aeruginosa from different clinical specimens based on several studies made in different countries and to discuss the distribution of $P$. aeruginosa infection and antibiotic resistance according to the gender of the patients and the type of specimen. ScienceDirect, PubMed and Google scholar were used during search to find published articles in English language. 15 articles from different countries about antimicrobial resistance patterns of $P$. aeruginosa were used in this article. Studies done between 2010 and 2020 were chosen. In this study Aminoglycosides (Amikacin), Piperacillin/Tazobactam and Polymyxins (Polymyxin-B and Colistin) were found to be the most effective drugs against $P$. aeruginosa. On the other hand, the highest resistance rate was against Cefuroxime, Ceftriaxone, Ampicillin, Ticarcillin/Clavulanic Acid, Amoxicillin/Clavulanic Acid, CoTrimoxazole, Ceftazidime, Cefepime, Aztreonam. Carbapenems (Meropenem and Imipenem) showed inconsistent results as they were found to be the most effective against $P$. aeruginosa in some places, while in others; they had the highest resistance rate.
\end{abstract}

Keywords: $P$. aeruginosa Resistance, $P$. aeruginosa, Antimicrobial Resistance, Antipseudomonal Drugs, Resistance Pattern and Clinical Isolates

\section{Introduction}

Pseudomonas aeruginosa is a gram-negative, aerobic rod bacteria (Ramos and Levesque, 2006). It is a freeliving pathogen that is commonly found in soil and water, infrequently being a part of microflora in healthy individuals (Ramos and Levesque, 2006; Fazeli et al., 2012). It is considered as one of the most challenging pathogens as being responsible for a wide range of infections including urinary tract infections, bone and joint infections, respiratory system infections, soft tissue infections, bacteremia, dermatitis and gastrointestinal infections (Fazeli et al., 2012). In addition, $P$. aeruginosa have been recognized as one of the most common and severe causes of nosocomial infections, since this pathogen has a strong ability to colonize in the hospital environment and easily spread between patients, along with the possibility of having an 
intrinsic or adapted antibiotic resistance that may lead to a high rate of mortality (Gellatly and Hancock, 2013; Lila et al., 2018).

Laboratory diagnosis of infections with $P$. aeruginosa can be done easily by culturing a clinical specimen on a variety of media, then easily recognized by its spreading, flat colonies, serrated edges and metallic sheen (LaBauve and Wargo, 2012).

$P$. aeruginosa infections can be treated with a single antibiotic (monotherapy) or a combination of antipseudomonal drugs. The selection of the antibiotic needed to treat $P$. aeruginosa infections depends on several factors. These factors include resistance surveillance, which plays a major role in patient management by providing data that influence clinical decision-making. Another factor is the host's medical condition whether it is cardiovascular infection, respiratory infection, bacteremia, CNS infection, ear or eye infection, urinary tract infection, GI infection or skin and soft tissue infection etc. Also, the effectiveness of the antibiotic should be taken into consideration as well as the prevention of antibiotic resistance, which is another important issue for choosing combination therapy or monotherapy (Giamarellou and Antoniadou, 2001; Johnson, 2015; Bassetti et al., 2018).

Several antibiotics cover $P$. aeruginosa. These include antipseudomonal Penicillins that involve Carbenicillin and Ticarcillin, Mezlocillin, Azlocillin and Piperacillin. The most commonly used antibiotic in this class is Piperacillin combined with Tazobactam. Another class is the antipseudomonal Cephalosporin that include Ceftazidime, Cefepime, Ceftazidime/Avibactam and Ceftolozane/Tazobactam. Furthermore, Aztreonam is the only available Monobactam that possesses antipseudomonal activity. As for Carbapenems; Imipenem, Doripenem and Meropenem, as well as some newer compounds such as Biapenem and Panipenem, have a wide spectrum of antimicrobial activity and can cover $P$. aeruginosa strains. Among the Fluoroquinolones available, Ciprofloxacin is the most active antibiotic and has a bactericidal effect against $P$. aeruginosa. Newer Quinolones such as Levofloxacin, Moxifloxacin and Gatifloxacin have low to moderate activity against pseudomonas infections (less active than Ciprofloxacin). Last class is Aminoglycosides including Gentamicin, Tobramycin and Amikacin, which have an important role in the therapy of serious $P$. aeruginosa infections (Giamarellou and Antoniadou, 2001; Bassetti et al., 2018).

Antimicrobial resistance has become one of the most important problems that face clinicians. According to the World Health Organization (WHO), antimicrobial resistance has been declared as a public health threat (Moremi et al., 2016). Hence, the study of antibiotic resistance patterns of microorganisms is considered very crucial to guide clinicians in empirical therapy during life-threatening infections. Moreover, that resistance patterns differ from region to another and changes continuously over time even in the same place which highlights the need for local annual resistance surveillances (Moremi et al., 2016; El-Azizi et al., 2005).

$P$. aeruginosa is one of the microorganisms that had developed a serious increase in resistance to many antipseudomonal drugs usually used in the treatment, which in turn has limited the availability of effective therapies for this infection (Ambroggio et al., 2012). This brings us to the big role of the annual local surveillance of $P$. aeruginosa resistance pattern in directing clinicians during antibiotic selection (Moremi et al., 2016).

The purpose of this study is to review antimicrobial resistance patterns of $P$. aeruginosa from different clinical specimens based on several studies conducted in different countries and to discuss the distribution of $P$. aeruginosa infection and antibiotic resistance according to the gender of the patients and the type of specimen, in order to guide the targeted approaches to help control antimicrobial resistance.

\section{Method}

\section{Search Strategy}

ScienceDirect, PubMed and Google scholar were used during search to find published articles about antimicrobial resistance patterns of $P$. aeruginosa between the period of 2010 and 2020. The free text words like "P. aeruginosa resistance," "P. aeruginosa," "antimicrobial resistance," "antipseudomonal drugs," "resistance pattern," and "clinical isolates" were searched using the Boolean operators "AND" or "OR." Additionally, the reference lists of the relevant studies were checked to see if these references include any other studies that might be used in this article.

\section{Study Selection}

We had access to many published articles about antimicrobial resistance patterns of $P$. aeruginosa. There was no requirement for ethical approval because we analyzed scientific literature already in the public domain. During selection, we only used studies published in English and we excluded any study done before 2010. For studies that were done in the same country or covered the same population as other studies, if they provided new information, we included them in the article and if not, we chose the study with better homogeneity when it was compared with other studies. The literature selection was performed independently by three researchers (N.H, M.J and A.P) and any disagreements were resolved by consensus.

\section{Data Abstraction}

Three researchers (N.H, M.J and A.P) independently extracted the following information: Year of publication, 
countries, gender, sample sizes, sample types, distribution of MDR strains and most and least effective drugs observed in each study. If no consensus can be reached on the disagreement, another reviewer would participate in the decision-making. We used standardized data extraction sheets made by Microsoft Excel 2019 for data extraction.

\section{Results Analysis}

The electronic searches identified 19 articles, 15 were used in data abstraction and four articles were used to support the discussion. Antibiotic sensitivity and resistance results in all studies reviewed were interpreted in accordance to the Clinical and Laboratory Standards Institute (CLSI). The results were divided into 5 subtitles, which were least effective antibiotic, most effective antibiotic, gender distribution, distribution of MDR strains and distribution in accordance to the type of specimen. The data of each subtitle was collected from different articles, then compared and discussed to give an explanation for the diversity of results in various countries and years regarding $P$. aeruginosa resistance pattern against commonly used antibiotics.

\section{Results}

A total of fifteen articles published in English, between the period of 2010 and 2020 were identified and reviewed, nine articles were prospective studies (Siddiqua et al., 2018; Farooq et al., 2019; Ahmadi et al.,
2016; Rustini et al., 2017; Senthamarai, 2014; Farhan et al., 2019; Ahmed et al., 2019; Al-Marzoqi and Al Taee, 2013; Khan and Faiz, 2016), four were descriptive cross sectional studies (Pokharel et al., 2019; Karami et al., 2020; Mahfoud et al., 2015; Alhusseini et al., 2019), one systemic review and meta-analysis study (Acar et al., 2019) and one retrospective study (Al-Tawfiq et al., 2020).

\section{Antibiotic Susceptibility Pattern}

Table 1 shows the percentage of susceptibility pattern of pseudomonas aeruginosa against different antibiotics. It shows how PA have a variation in sensitivity and resistance pattern for different antibiotics in different regions. For example, meropenem have high sensitivity to PA in most countries while in Saudi Arabia have 30\% resistance to meropenem (Khan and Faiz, 2016). There are some articles were done in the same country but in different periods and they showed different resistance pattern rate that were in Iran (Ahmadi et al., 2016; Karami et al., 2020), Iraq (Al-Marzoqi and Al Taee, 2013; Alhusseini et al., 2019) and Saudi Arabia (Khan and Faiz, 2016; Al-Tawfiq et al., 2020).

\section{Distribution of Isolates in Accordance to Type of Specimen}

Thirteen out of fifteen articles showed the distribution of isolates in accordance to type of specimen as in Table 2. In general, the distribution showed that the most occurring source of $P$. aeruginosa isolates were sputum, wound, urine and tracheal aspirate.

Table 1: Percentage of susceptibility pattern of Pseudomonas aeruginosa against different antibiotics

\begin{tabular}{|c|c|c|c|}
\hline Country & Year & Antibiotic Resistance rate & Antibiotic Sensitivity rate \\
\hline $\begin{array}{l}\text { Bangladesh (Siddiqua et al., } \\
\text { 2018) }\end{array}$ & January 2015-October 2016 & Cefuroxime $96 \%$ Cotrimoxazole $91 \%$ & $\begin{array}{l}\text { Meropenem, Ciprofloxacin, Amikacin } \\
\text { and Imipenem ( } 76 \text { to } 87 \% \text { ) }\end{array}$ \\
\hline $\begin{array}{l}\text { Indonesia (Rustini et al., } \\
\text { 2017) }\end{array}$ & 2017 & $\begin{array}{l}\text { Ceftriaxone } 44.21 \% \text {, Cefotaxime } \\
41.05 \% \text {, Cefoperazone } 37.89 \%\end{array}$ & Amikacin $89.47 \%$ \\
\hline Pakistan (Farooq et al., 2019) & October 2017-April 2018 & $\begin{array}{l}\text { Imipenem } 81.6 \% \text {, Ciprofloxacin } \\
80.4 \% \text {, Ceftazidime } 78 \%\end{array}$ & Colisitin $100 \%$ \\
\hline Iran (Ahmadi et al., 2016) & June 2014- October 2015 & Ampicillin 93\% & Meropenem $97.7 \%$ \\
\hline Iran (Karami et al., 2020) & January 2017- December 2017 & $\begin{array}{l}\text { Ticarcillin/Clavulanic } \\
\text { Acid } 75.8 \% \text {, Aztreonam } 72.4 \%\end{array}$ & Colisitn $100 \%$ \\
\hline Nepal (Pokharel et al., 2019) & February 2018-May 2018 & Co-Trimoxazole $80.4 \%$ & Polymyxin-B $100 \%$, Colistin $100 \%$ \\
\hline India (Senthamarai, 2014) & February 2012-January 2013 & $\begin{array}{l}\text { Ceftazidime } 65.38 \% \text {, Ciprofloxacin } \\
61.53 \% \text {, Piperacillin } 59.61 \%\end{array}$ & Imipenem $80.77 \%$ \\
\hline Egypt (Farhan et al., 2019) & October 2016-February 2018 & $\begin{array}{l}\text { Ceftazidime } 60 \% \text {, Tobramycin } \\
\text { less than } 60 \% \text {, Aztreonam } 57 \%\end{array}$ & Imipenem and Meropenem \\
\hline Qatar (Ahmed et al., 2019) & October 2014-September 2015 & $\begin{array}{l}\text { Cefepime } 96.6 \% \text {, Ciprofloxacin 91\%, } \\
\text { Piperacillin/Tazobactam } 90.7 \%\end{array}$ & Colisitn $96.6 \%$ \\
\hline Syria (Mahfoud et al., 2015) & $\begin{array}{l}\text { September 2011- } \\
\text { September } 2012\end{array}$ & $\begin{array}{l}\text { Amoxicillin/Clavulanic acid } 97.7 \% \text {, } \\
\text { Nitrofurantoin } 96.8 \% \text {, } \\
\text { Clarithromycin } 96.2 \%\end{array}$ & Colistin $89.1 \%$ \\
\hline $\begin{array}{l}\text { Iraq (Al-Marzoqi and } \\
\text { Al Taee, 2013) }\end{array}$ & $\begin{array}{l}\text { September 2012- } \\
\text { February } 2013\end{array}$ & $\begin{array}{l}\text { Penicillin Erythromycin Norfloxacin, } \\
\text { Amoxicillin + Clavulanic acid } \\
\text { Azithromycin Piperacillin }\end{array}$ & Amikacin, Erythromycin Penicillin \\
\hline Iraq (Alhusseini et al., 2019) & 2019 & Amoxicillin + Clavulanic acid $90.74 \%$ & Imipenem and Meropenem $68.5 \%$ \\
\hline Turkey (Acar et al., 2019) & 2007-2016 & Aztreonam 57.5\% & - \\
\hline $\begin{array}{l}\text { Saudi Arabia (Khan and } \\
\text { Faiz, 2016) }\end{array}$ & August 2013- January 2014 & Meropenem $30.6 \%$ & Piperacillin/Tazobactam $95.1 \%$ \\
\hline $\begin{array}{l}\text { Saudi Arabia } \\
\text { (Al-Tawfiq } \text { et al., 2020) }\end{array}$ & $2017-2018$ & $\begin{array}{l}\text { Ciprofloxacin 26\%, } \\
\text { Meropenem and Imipenem 25\% }\end{array}$ & Amikacin $91 \%-94 \%$ \\
\hline
\end{tabular}




\begin{tabular}{|c|c|c|c|c|c|c|c|c|c|c|c|c|c|c|c|}
\hline \multirow[b]{2}{*}{ Country } & \multirow[b]{2}{*}{ Year } & \multirow{2}{*}{$\begin{array}{l}\text { \# of } \\
\text { sample } \\
\text { isolates }\end{array}$} & \multicolumn{13}{|c|}{ Distribution of isolates according to the type of specimen } \\
\hline & & & $\begin{array}{l}\text { wound } \\
\text { sample }\end{array}$ & Pus & Urine & Sputum & Swab & Blood & Stool & Tracheal & $\begin{array}{l}\text { Ear } \\
\text { swab }\end{array}$ & $\begin{array}{l}\text { Burn } \\
\text { swab }\end{array}$ & $\mathrm{CSF}$ & $\begin{array}{l}\text { Pleural } \\
\text { fluid }\end{array}$ & $\begin{array}{l}\text { Catheter } \\
\text { tip }\end{array}$ \\
\hline $\begin{array}{l}\text { Bangladesh } \\
\text { (Siddiqua et al., 2018) }\end{array}$ & $\begin{array}{l}\text { January 2015- } \\
\text { october } 2016\end{array}$ & 138 & $64.49 \%$ & $13.04 \%$ & $12.31 \%$ & - & - & - & - & - & - & - & - & - & - \\
\hline $\begin{array}{l}\text { Indonesia } \\
\text { (Rustini } \text { et al., 2017) }\end{array}$ & 2017 & 95 & - & $24.2 \%$ & $10.5 \%$ & $36.8 \%$ & $23.15 \%$ & $3.15 \%$ & $2.1 \%$ & - & - & - & - & - & - \\
\hline $\begin{array}{l}\text { Pakistan } \\
\text { (Farooq et al., 2019) }\end{array}$ & $\begin{array}{l}\text { October 2017- } \\
\text { April } 2018\end{array}$ & 167 & - & $34 \%$ & $18.6 \%$ & - & $2.1 \%$ & - & - & $20.6 \%$ & - & - & - & - & - \\
\hline $\begin{array}{l}\text { Iran (Ahmadi et al., } \\
\text { 2016; Karami et al., }\end{array}$ & $\begin{array}{l}\text { June 2014- } \\
\text { October } 2015\end{array}$ & 172 & - & - & - & - & - & - & - & - & - & $66.6 \%$ & - & - & - \\
\hline 2020) & $\begin{array}{l}\text { January 2017- } \\
\text { December } 2017\end{array}$ & 78 & $22.41 \%$ & - & $41.38 \%$ & - & - & $20.69 \%$ & - & - & - & - & $15.52 \%$ & - & - \\
\hline $\begin{array}{l}\text { Nepal (Pokharel et al., } \\
\text { 2019) }\end{array}$ & $\begin{array}{l}\text { February- } \\
\text { May } 2018\end{array}$ & 46 & $13.04 \%$ & - & $15.21 \%$ & $39.13 \%$ & - & $8.69 \%$ & - & $10.88 \%$ & - & - & - & $2.17 \%$ & $10.88 \%$ \\
\hline $\begin{array}{l}\text { India (Senthamarai, } \\
\text { 2014) }\end{array}$ & $\begin{array}{l}\text { February 2012- } \\
\text { Jan } 2013\end{array}$ & 104 & - & $47.11 \%$ & $12.5 \%$ & $36.53 \%$ & - & $3.84 \%$ & - & - & - & - & - & - & - \\
\hline $\begin{array}{l}\text { Egypt (Farhan et al., } \\
\text { 2019) }\end{array}$ & $\begin{array}{l}\text { October 2016- } \\
\text { February } 2018\end{array}$ & 150 & $43.33 \%$ & - & $4 \%$ & $5.33 \%$ & - & - & $5.33 \%$ & - & $26 \%$ & $3.33 \%$ & - & - & - \\
\hline $\begin{array}{l}\text { Syria (Mahfoud et al., } \\
\text { 2015) }\end{array}$ & $\begin{array}{l}\text { September 2011- } \\
\text { September } 2012\end{array}$ & 177 & - & - & $22 \%$ & - & - & - & - & $\begin{array}{l}78 \% \text { lower } \\
\text { respiratoy } \\
\text { tract }\end{array}$ & - & - & - & - & - \\
\hline $\begin{array}{l}\text { Iraq (Al-Marzoqi and } \\
\mathrm{Al} \text { Taee, 2013; }\end{array}$ & $\begin{array}{l}\text { September 2012- } \\
\text { February } 2013\end{array}$ & 285 & $22.46 \%$ & - & $22.11 \%$ & - & $18.6 \%$ & - & - & $15.09 \%$ & - & - & - & - & - \\
\hline Alhusseini et al., 2019) & 2019 & 54 & $18.51 \%$ & - & $5.55 \%$ & - & - & $3.7 \%$ & - & - & $3.7 \%$ & - & - & - & $3.7 \%$ \\
\hline $\begin{array}{l}\text { Saudi Arabia } \\
\text { (Khan and Faiz, 2016) }\end{array}$ & $\begin{array}{l}\text { August 2013- } \\
\text { January } 2014\end{array}$ & 121 & - & - & $10.74 \%$ & - & - & $3.36 \%$ & - & $43.8 \%$ & $2.48 \%$ & $1.65 \%$ & - & - & - \\
\hline
\end{tabular}

Table 3: Distribution of the $P$. aeruginosa isolates according to the gender

\begin{tabular}{|c|c|c|c|c|c|}
\hline \multirow[b]{2}{*}{ Country } & \multirow[b]{2}{*}{ Year } & \multirow[b]{2}{*}{$\begin{array}{l}\text { \# of sample } \\
\text { isolates }\end{array}$} & \multicolumn{2}{|c|}{ Distribution of isolates according to Gender } & \multirow{2}{*}{$\begin{array}{l}\text { Ratio } \\
\text { Male to } \\
\text { female }\end{array}$} \\
\hline & & & Male (\%) & Female $(\%)$ & \\
\hline $\begin{array}{l}\text { Bangladesh } \\
\text { (Siddiqua et al., 2018) }\end{array}$ & January 2015-october 2016 & 138 & 75.36 & 24.64 & $3: 1$ \\
\hline Iran (Ahmadi et al., & June 2014-October 2015 & 172 & 35.8 & 64.2 & $1: 1.7$ \\
\hline 2016; Karami et al., 2020) & January 2017-December 2017 & 78 & 58.6 & 41.4 & $1.4: 1$ \\
\hline India (Senthamarai, 2014) & February 2012 to January 2013 & 104 & 55.76 & 44.23 & $1.2: 1$ \\
\hline $\begin{array}{l}\text { Iraq Al-Marzoqi and } \\
\text { Al Taee, 2013) }\end{array}$ & September 2012-February 2013 & 285 & 74.04 & 25.96 & $3: 1$ \\
\hline
\end{tabular}

\section{Distribution of Isolates in Accordance to Gender}

In this article, five countries studied the distribution of isolates in accordance to gender. Table 3 describes the percentage of distribution of isolates in males and females, it also showed that Iran (Ahmadi et al., 2016; Karami et al., 2020) conducted two studies in different periods and had different percentage distribution in accordance to gender.

\section{MDRPA}

Multi-drug resistant $P$. aeruginosa was defined, according to the studies included in this report, as the bacteria that were resistant to at least three antibiotics. MDRPA prevalence was reported in seven of the collected articles. The distribution of MDRPA among the specimens was found to be as follows: Pakistan, (55\%) (Farooq et al., 2019); Indonesia, (36\%) (Rustini et al., 2017); India (41.35\%) (Senthamarai, 2014); Egypt (66.6\%) (Farhan et al., 2019); Qatar (8.1\%) (Ahmed et al., 2019); Saudi Arabia (10.7\%) (Khan and Faiz, 2016). In Nepal MDRPA prevalence was reported according to the type of specimen where it found to be the highest in tracheal aspirate specimens (100\%) and the lowest in pleural fluid samples (0\%) (Pokharel et al., 2019). Female to male ratio for MDRPA prevalence was reported in two of the included articles as it was (1.17:1) in Pakistan (Farooq et al., 2019) and (1:3) in Qatar (Ahmed et al., 2019). Further information was reported in Pakistan regarding distribution of MDRPA according to medical ward as it was the highest in surgical ward $(27.1 \%)$ and the lowest in the gynecology ward $(4.1 \%)$ (Farooq et al., 2019).

\section{Discussion}

Periodic surveillance and monitoring of antimicrobial resistance of $P$. aeruginosa is very important in order to provide an updated information about the current activity of commonly used antipseudomonal drugs in the studied region. Reviewing the surveillances that were done in different countries allows the identification of trends in $P$. aeruginosa resistance at the national and global levels and assists the development of targeted approaches to help control antimicrobial resistance.

This study focused mainly on the resistance pattern of $P$. aeruginosa against different drugs in different 
countries. It was observed that the highest resistance rate was against Cefuroxime in Bangladesh (Siddiqua et al., 2018), Ceftriaxone in Indonesia (Rustini et al., 2017), Imipenem in Pakistan (Farooq et al., 2019), Ampicillin (Ahmadi et al., 2016) and Ticarcillin/Clavulanic Acid (Karami et al., 2020) in Iran, Co-Trimoxazole in Nepal (Pokharel et al., 2019), Ceftazidime in India and Egypt (Senthamarai, 2014; Farhan et al., 2019), Cefepime in Qatar (Ahmed et al., 2019), Amoxicillin/Clavulanic Acid in Syria (Mahfoud et al., 2015), Penicillin and Amoxicillin/Clavulanic Acid in Iraq (Alhusseini et al., 2019), Aztreonam in Turkey (Acar et al., 2019) and Meropenem (Khan and Faiz, 2016), Ciprofloxacin followed by Meropenem and Imipenem (Al-Tawfiq et al., 2020) then both Carbapenems (Al-Tawfiq et al., 2020) in Saudi Arabia.

A notable finding was the high resistance rate against Imipenem (81.6\%) in Pakistan (Farooq et al., 2019). It is evident that MDR strains of pseudomonas are accelerating in Pakistan (Farooq et al., 2019). This might be due to the fact that several drugs including Imipenem are widely prescribed in secondary and tertiary care hospitals, since there is a causal relationship between antimicrobials use and development of resistance (Farooq et al., 2019). Moreover, in Saudi Arabia, the highest resistance rate in 2013-2014 was against Meropenem (30.6\%) (Khan and Faiz, 2016). In 20172018, Ciprofloxacin showed (26\%) resistance to PA, whereas Meropenem and Imipenem there's resistance rate was dropped to (25\%) (Al-Tawfiq et al., 2020). The study done in Saudi Arabia is very similar to Pakistan as the results shown. Although the resistance pattern of $P$. aeruginosa did not change significantly over time in Saudi Arabia (Khan and Faiz, 2016; Al-Tawfiq et al., 2020), there still was a high resistance rate against Carbapenems, which should not be used as a first line treatment for $P$. aeruginosa infections. This resistance indicates probable overuse of broad-spectrum antibiotics like Carbapenems, an issue that needs to be addressed by each institution with regard to regulations on use of broad-spectrum antibiotics.

Ceftazidime is a third generation Cephalosporin that is the most active Cephalosporin available against $P$. aeruginosa (Richards and Brogden, 1985), however, India (Senthamarai, 2014) and Egypt (Farhan et al., 2019) had the highest resistance rates against it which are $(65.38 \%)$ and $(60 \%)$ respectively. This represents a challenge for antimicrobial therapy patients and might be caused by the indiscriminate use of third generation Cephalosporin as broad spectrum empirical therapy and the secretion of Extended Spectrum Beta-Lactamases enzymes (ESBL) mediate the resistance by hydrolysis of $\beta$-lactam ring of $\beta$-lactam antibiotics (Richards and Brogden, 1985). Cefepime is a fourth generation Cephalosporin that has an antipseudomonal activity and was found to be the least effective drug against $P$. aeruginosa in Qatar with a resistance rate of (96.6\%), which might be due to higher consumption of this drug compared to others (Ahmed et al., 2019).

Aztreonam is the only available Monobactam that has intermediate activity against $P$. aeruginosa and can be a useful alternative to Aminoglycosides or third generation Cephalosporin in patients with serious Gram-negative infections (Richards and Brogden, 1985). Studies done in Turkey (Acar et al., 2019) showed that the highest resistance rates of $P$. aeruginosa were against Aztreonam $(57.5 \%)$ and they conclude that the rates of antibiotic resistance in pathogenic $P$. aeruginosa strains are substantially high in Turkey and continue to increase compared with previous years.

Penicillin, Ampicillin, Amoxicillin, Cefuroxime and Ceftriaxone are all $\beta$-lactams that do not cover $P$. aeruginosa and has no effect against infections caused by it because they are all inactivated by beta-lactamases, which are produced by $P$. aeruginosa or due to the overexpression of efflux pumps. According to the studies done, these drugs were the least effective in Iraq, Iran, Syria, Bangladesh and Indonesia respectively. In addition, Co-Trimoxazole is a folate antagonist that is also not active against $P$. aeruginosa, which was found to have the highest resistance rate $(80.4 \%)$ in Nepal (Pokharel et al., 2019). The misuse of these antibiotics can be a key factor contributing to the emergence of antibiotic resistance. On the other hand, Ticarcillin is an Extended-Spectrum Penicillin that is more resistant to cleavage by gram-negative beta-lactamases than other Penicillins and can cover $P$. aeruginosa (Richards and Brogden, 1985). In 2017, in Iran, it was found to have the highest resistance rate $(75.8 \%)$. This is due to the biofilm formation of $P$. aeruginosa, which leads to loss of antibacterial susceptibility (Karami et al., 2020).

Healthcare providers need annual surveillances for antipseudomonal drug resistance patterns as they have a very essential role in identifying the most effective antipseudomonal drugs. In this study Carbapenems (Meropenem and Imipenim), Aminoglycosides (Amikacin), Piparacillin/Tazobactam and Polymyxins (Polymyxin-B and Colistin) were found to be the most effective drugs against $P$. aeruginosa regarding the included studies.

In Bangladesh, Iran, India, Egypt and Iraq, Carbapenems were found to be the most effective drugs against $P$. aeruginosa. Meropenem showed the highest susceptibility rate $(97.7 \%)$ in Iran during the period of June 2014 and October 2015 (Ahmadi et al., 2016), while another study was conducted in Iran from January 2017 to December 2017 showed a significant decrease in the susceptibility rate to Meropenem (48.2\%) (Karami et al., 2020). In India Imipenem $(80.77 \%)$ was detected to be the most effective 
antipseudomonal drug (Senthamarai, 2014). Not to mention that Meropenem and Imipenem both were equally observed with the highest susceptibility rate in Egypt with more than 90\% (Farhan et al., 2019), followed by Bangladesh with a rate of (76-87\%) (Siddiqua et al., 2018) and Iraq during 2019 was with the lowest susceptibility rate of (68.52\%) (Alhusseini et al., 2019). Susceptibility rates differences among the different countries and periods are mainly related to the prescription habits and drug use in each country.

Among the several studies included in this study, Aminoglycosides, especially (Amikacin), showed a significant high susceptibility rate in some countries. In Saudi Arabia, Amikacin had the highest susceptibility rate (94\%) (Al-Tawfiq et al., 2020), followed by Indonesia with a susceptibility rate of $(89.47 \%)$ (Rustini et al., 2017), while Bangladesh with susceptibility range of (7687\%) (Siddiqua et al., 2018) and Nepal despite being colistin the most effective antibiotic, it showed (71.7\%) susceptibility to Amikacin (Pokharel et al., 2019). This difference in susceptibility rates and that some countries were observed with less susceptibility rate to amikacin earlier than the others may be due to the overuse of Amikacin, which will increase the risk of $P$. aeruginosa resistance to this drug in the future. This will, in turn, limit the drug choices that can be used to treat $P$. aeruginosa infections in some countries. Moreover Amikacin was detected to be the most effective drug in Iraq during the period (Al-Marzoqi and Al Taee, 2013).

Piperacillin/Tazobactam was found to be the most effective drug against $P$. aeruginosa infections in Makkah and Jeddah with susceptibility rate of $(95.1 \%)$ (Khan and Faiz, 2016). This finding was unexpected since Piperacillin/Tazobactam is considered one of the first line and the most commonly used drugs against $P$. aeruginosa infections worldwide, while, on the other hand, Meropenem and Imipenem, which are two of the last line drugs used against $P$. aeruginosa were observed to be the least effective. These unexpected results were mainly due to different antibiotics prescriptions habits in different countries (Khan and Faiz, 2016). On the other hand, Piperacillin/Tazobactam was one of the most effective drugs in Nepal with a rate of (76\%) (Pokharel et al., 2019).

Polymyxins (Polymyxin-B and Colistin) are usually used as a last line in cases of contraindications and if the first line antibiotics are ineffective. It was noted that Colistin was $(100 \%)$ effective against $P$. aeruginosa in Pakistan (Farooq et al., 2019), Iran (Karami et al., 2020) and Nepal (Pokharel et al., 2019). In contrast, Colistin was observed to be effective with a susceptibility rate of $(96.6 \%)$ in Qatar (Ahmed et al., 2019) and with a susceptibility rate of $(89.1 \%)$ in Syria (Mahfoud et al., 2015). Decreased susceptibility to Colistin in Syria is due to the overuse of this antibiotic, so this will increase the risk that this drug will not be available in the future, despite the fact that it has considered a broad spectrum antibiotic and usually used as last line in therapy.

Some of the reviewed studies have shown that males were more susceptible to be infected by $P$. aeruginosa than females. This was obvious when the distribution of $P$. aeruginosa clinical isolates was compared according to gender and gave two trends in the ratio of infection when looking gender wise. In Bangladesh (Siddiqua et al., 2018), Iraq (Alhusseini et al., 2019) and Qatar (Ahmed et al., 2019) the ratio of $P$. aeruginosa infection (male to female) was found to be $(3: 1)$. While in Iran (Karami et al., 2020) and India (Senthamarai, 2014) the ratio of $P$. aeruginosa infection (male to female) was found to be approximately (1.4:1). Both trends show male preponderance in being infected by $P$. aeruginosa, which can be explained by the fact that males are more exposed to outside environment than females, as their activity and nature of work can be associated with higher exposure to soil, water, or any moistened environments in where this bacterium favors to grow (Siddiqua et al., 2018; Senthamarai, 2014; Ahmed et al., 2019).

Two studies that were done in Pakistan and Qatar have compared the frequency of MDR $P$. aeruginosa according to the gender. In Pakistan MDR P. aeruginosa was predominant in females as compared to males (Farooq et al., 2019), while in Qatar MDR P. aeruginosa was predominant in males as compared to females (Khan and Faiz, 2016). These contrasting results regarding the distribution of MDR $P$. aeruginosa between males and females can be explained by the difference in gender prevalence with geographical variation and study period (Farooq et al., 2019).

The general, distribution rank of $P$. aeruginosa clinical isolates according to the type of specimens collected in different countries revealed that respiratory tract specimens was the most occurring source of $P$. aeruginosa isolates, followed by wound swab and urine, which is generally similar to the described rank that was established based on isolates obtained in the Global SENTRY Antimicrobial Surveillance Program (Gales et al., 2001). Infection with $P$. aeruginosa can develop in many anatomical sites, but as $P$. aeruginosa is ubiquitous and favors moist environments, its most common infections occur in hospitalized patients by colonizing in the moist area of the skin and the upper respiratory tract and this is due to its ability to grow in simple aqueous solutions resulting in contamination of respiratory therapy and anesthesia equipment, intravenous fluid and even distilled water (Bush and Perez, 2020).

\section{Conclusion}

Pseudomonas aeruginosa is a gram-negative, aerobic rod bacterium and it is one of the most commonly isolated pathogens from clinical specimens. 
Periodic surveillance of $P$. aeruginosa resistance patterns is essential in order to provide updated information about the effectiveness of antipseudomonal drugs that are commonly used in the studied country. The high resistance rate that had been observed through this literature review against antipseudomonal drugs indicates the need to develop targeted approaches to help control antimicrobial resistance.

\section{Acknowledgement}

We would like to express our appreciation to the Professors at the Faculty of Pharmacy, Nursing and Health Professions, Birzeit University, Palestine for their support.

\section{Limitations}

A limited number of related recent articles were found on the used search engines, which was the reason for including older studies.

\section{Data Availability}

The data used to support the findings of this study are available from the corresponding author upon request.

\section{Authors Contributions}

All authors equally contributed in this work.

\section{Conflict of Interest}

The authors state that they do not present any conflict of interests in the present research.

\section{References}

Acar, A., Karaahmetoğlu, G., Akalın, H., \& Altay, A. F. (2019). Pooled prevalence and trends of antimicrobial resistance in Pseudomonas aeruginosa clinical isolates over the past 10 years in Turkey: A meta-analysis. Journal of global antimicrobial resistance, 18 , 64-70.

Ahmadi, K., Hashemian, A. M., Pouryaghobi, S. M., Akhavan, R., Rozmina, S., \& Bolvardi, E. (2016). RETRACTED ARTICLE: Antibiotic Resistance Properties of Pseudomonas aeruginosa Isolated From Cases of Superficial Infections at the Emergency Unit. Jundishapur Journal of Microbiology, 9(1).

Ahmed, M. S., Hassan, A. A. I., Jarir, S. A., Hadi, H. A., Bansal, D., Wahab, A. A., ... \& Alyazidi, M. A. (2019). Emergence of multidrug-and pandrugresistant Pseudomonas aeruginosa from five hospitals in Qatar. Infection Prevention in Practice, 1(3-4), 100027.
Alhusseini, L. B., Maleki, A., Kouhsari, E., Ghafourian, S., Mahmoudi, M., \& Al Marjani, M. F. (2019). Evaluation of type II toxin-antitoxin systems, antibiotic resistance and biofilm production in clinical MDR Pseudomonas aeruginosa isolates in Iraq. Gene Reports, 17, 100546.

Al-Marzoqi, A. H., \& Al Taee, Z. M. (2013). Pseudomonas aeruginosa: Antibiotic resistance pattern to different isolates in Al-Hillah city, Iraq. Journal of Natural Sciences Research, 3(3), 69-74.

Al-Tawfiq, J. A., Rabaan, A. A., Saunar, J. V., \& Bazzi, A. M. (2020). Antimicrobial resistance of gram-negative bacteria: A six-year longitudinal study in a hospital in Saudi Arabia. Journal of Infection and Public Health.

Ambroggio, L., Tabb, L. P., O’MEARA, T. I. M. O. T. H. Y., Sheffler-Collins, S., McGowan, K. L., \& Shah, S. S. (2012). Influence of Antibiotic Susceptibility Patterns on Empiric Antibiotic Prescribing for Children Hospitalized with Community Acquired Pneumonia. The Pediatric infectious disease journal, 31(4), 331.

Bassetti, M., Vena, A., Croxatto, A., Righi, E., \& Guery, B. (2018). How to manage Pseudomonas aeruginosa infections. Drugs in context, 7.

Bush, L. M., \& Perez, M. T. (2020). Typhoid FeverPseudomonas and Related Infections - Infectious Diseases - Merck Manuals Professional Edition. https://www.merckmanuals.com/professional/infecti ous-diseases/gram-negative-bacilli/typhoid-fever

El-Azizi, M., Mushtaq, A., Drake, C., Lawhorn, J., Barenfanger, J., Verhulst, S., \& Khardori, N. (2005). Evaluating antibiograms to monitor drug resistance. Emerging infectious diseases, 11(8), 1301.

Farhan, S. M., Ibrahim, R. A., Mahran, K. M., Hetta, H. F., \& Abd El-Baky, R. M. (2019). Antimicrobial resistance pattern and molecular genetic distribution of metallo- $\beta$-lactamases producing Pseudomonas aeruginosa isolated from hospitals in Minia, Egypt. Infection and Drug Resistance, 12, 2125.

Farooq, L., Memon, Z., Ismail, M. O., \& Sadiq, S. (2019). Frequency and antibiogram of multi-drug resistant pseudomonas aeruginosa in a Tertiary Care Hospital of Pakistan. Pakistan journal of medical sciences, 35(6), 1622.

Fazeli, H., Akbari, R., Moghim, S., Narimani, T., Arabestani, M. R., \& Ghoddousi, A. R. (2012). Pseudomonas aeruginosa infections in patients, hospital means and personnel's specimens. Journal of research in medical sciences: the official journal of Isfahan University of Medical Sciences, 17(4), 332. 
Gales, A. C., Jones, R. N., Turnidge, J., Rennie, R., \& Ramphal, R. (2001). Characterization of Pseudomonas aeruginosa isolates: occurrence rates, antimicrobial susceptibility patterns and molecular typing in the global SENTRY Antimicrobial Surveillance Program, 1997-1999. Clinical Infectious Diseases, 32(Supplement_2), S146-S155.

Gellatly, S. L., \& Hancock, R. E. (2013). Pseudomonas aeruginosa: new insights into pathogenesis and host defenses. Pathogens and disease, 67(3), 159-173.

Giamarellou, H., \& Antoniadou, A. (2001). Antipseudomonal antibiotics. Medical Clinics of North America, 85(1), 19-42.

Johnson, A. P. (2015). Surveillance of antibiotic resistance. Philosophical Transactions of the Royal Society B: Biological Sciences, 370(1670), 20140080.

Karami, P., Khaledi, A., Mashoof, R. Y., Yaghoobi, M. H., Karami, M., Dastan, D., \& Alikhani, M. Y. (2020). The correlation between biofilm formation capability and antibiotic resistance pattern in Pseudomonas aeruginosa. Gene Reports, 18, 100561.

Khan, M. A., \& Faiz, A. (2016). Antimicrobial resistance patterns of Pseudomonas aeruginosa in tertiary care hospitals of Makkah and Jeddah. Annals of Saudi medicine, 36(1), 23-28.

LaBauve, A. E., \& Wargo, M. J. (2012). Growth and laboratory maintenance of Pseudomonas aeruginosa. Current protocols in microbiology, 25(1), 6E-1.

Lila, G., Mulliqi, G., Raka, L., Kurti, A., Bajrami, R., \& Azizi, E. (2018). Molecular epidemiology of Pseudomonas aeruginosa in University clinical center of Kosovo. Infection and drug resistance, 11, 2039.
Mahfoud, M., Al Najjar, M., \& Hamzeh, A. R. (2015). Multidrug resistance in Pseudomonas aeruginosa isolated from nosocomial respiratory and urinary infections in Aleppo, Syria. The Journal of Infection in Developing Countries, 9(02), 210-213.

Moremi, N., Claus, H., \& Mshana, S. E. (2016). Antimicrobial resistance pattern: a report of microbiological cultures at a tertiary hospital in Tanzania. BMC infectious diseases, 16(1), 756.

Pokharel, K., Dawadi, B. R., Bhatt, C. P., \& Gupte, S. (2019). Prevalence of pseudomonas aeruginosa and its antibiotic sensitivity pattern. Journal of Nepal Health Research Council, 17(1), 109-113.

Ramos, J. L., \& Levesque, R. C. (Eds.). (2006). Pseudomonas: Volume 4: Molecular Biology of Emerging Issues (Vol. 4). Springer Science \& Business Media.

Richards, D. M., \& Brogden, R. N. (1985). Ceftazidime. Drugs, 29(2), 105-161.

Rustini, R. U. S. T. I. N. I., JAMSARI, J., MARLINA, M., ZUBIR, N., \& YULIANDRA, Y. (2017). Antibacterial resistance pattern of Pseudomonas aeruginosa isolated from clinical samples at a General Hospital in Padang, West Sumatra, Indonesia. Asian J Pharm Clin Res, 10(8), 158-160.

Senthamarai, S. (2014). Resistance pattern of Pseudomonas aeruginosa in a tertiary care hospital of Kanchipuram, Tamilnadu, India. Journal of clinical and diagnostic research: JCDR, 8(5), DC30.

Siddiqua, M., Alam, A. N., Akter, S., \& Ferdousi, R. S. (2018). Antibiotic resistance pattern in pseudomonas aeruginosa isolated from a private Medical College Hospital. KYAMC Journal, 9(1), 16-19. 